\title{
A Theoretical Study of Tridentenes
}

\author{
Takayuki OHMAE
}

Department of Human Nutrition, Faculty of Nursing and Human Nutrition, Yamaguchi Prefectural University, 3-2-1 Sakurabatake, Yamaguchi City, Yamaguchi 753-8502 Japan ohmae@yamaguchi-pu.ac.jp

As substances corresponding to annulenes in Y-aromatic compounds, tridentenes were proposed by the authors. In this description, by revision of existing papers, a discussion on the magic number of tridentenes, which corresponds to Hückel's $4 \mathrm{~N}+2$ rule, and arguments regarding typhoon tridentene and cyclone tridentene, which are expected to have stereoselective inclusion forming ability, are presented.

\section{§ I Study of Magic Numbers In Y-Aromaticity $\S \mathrm{I}-1$ Introduction}

The concept of Y-aromaticity was introduced to explain the strong basicity of guanidine [1]. This concept, wherein the energetic stability of an organic molecule is determined by the branching structure, irrespective of the ring structure, is unprecedented and new, so multiple theoretical studies on Y-aromaticity have been conducted [2-7]. However, in contrast to benzene-system aromatic compounds, the practical application of Y-aromatic compounds remains static. The likely reason for this is that the typical compounds in Y-aromatic compounds those that correspond to annulene in a benzene-system aromatic compound have not been fully studied.

Therefore, in this study the author proposes a system where trimethylenemethane $[1,8]$ is extended so it becomes a typical compound corresponding to annulene in Y-aromatic compounds. The results of the theoretical study on this system are reported herein.

Specifically, the magic number [9] (corresponding to the $4 \mathrm{~N}+2$ rule) that predicts the number of electrons generating the aromaticity in annulene, is obtained by imposing a closed shell condition on a typical compound in Y-aromatic compounds. Furthermore, whether the magic number obtained becomes an effective rule in predicting the Y-aromaticity is investigated by obtaining the energy difference from the reference system. Note that Y-aromatic compounds do not have a ring structure, so the topological resonance energy that is commonly used to investigate the existence of aromaticity cannot be used [10,11]. Therefore, in the present study, perturbation theory is applied to the branch structure of the Y-aromatic compounds. The results allowed for the investigation of the effectiveness of the magic number by using a straight chain conjugated system as a reference system.

This discussion is important for clarifying the origin of the energetical stability in Y-aromatic compounds. The propagator method in the Hückel approximation that systematically investigates the relationship between the structure and energy is utilized in this study as the analytical method $[12,13]$. Hückel approximation is an extremely simplified method in which the electron-electron interaction is averaged to a single interaction. Nevertheless, since this simplification enables direct association of the Hückel Hamiltonian with the adjacency matrix for the molecular graph of the conjugated system, it is effective in investigating the relationship between the shape and the energy of the conjugated system [14].

As a result of this investigation, if the structural characteristics of the conjugated systems that produce the energetical stability in Y-aromatic compounds are clarified, research on the design and synthesis of useful Y-aromatic compounds (i.e., bulky Y-aromatic compounds that are candidates for ionic fluid) can be expected to take place in the future. 


\section{$\S \mathrm{I}-2$ Results and discussion}

\section{§ I-2.1 Typical compounds}

The system shown in Fig. 1 is proposed as a typical compound corresponding to annulene in Y-aromatic compounds.

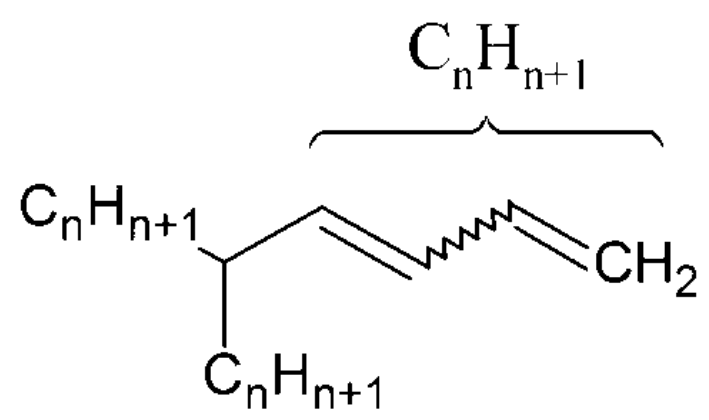

Fig. 1 Model system of Y-Aromatic compounds.

This typical compound has a structure where the three methylene groups in trimethylenemethane are respectively substituted by chain conjugated systems composed of $n$ carbon atoms. Hereafter, it is simply called n-tridentene after its triaene structure.

\section{§ I-2.2 Propagator method}

In the theoretical calculation of n-tridentene, this study utilizes the propagator method in the Hückel approximation $[12,13]$. In this section, the propagator method is explained in a simple manner.

The propagator $[\mathbf{G}(\mathrm{z})]$ is defined by the following equation:

$$
(\mathrm{z}-\mathbf{H}) \mathbf{G}(\mathrm{z})=\mathbf{1},
$$

where $\mathbf{z}$ is the energy parameter and $\mathbf{H}$ is the Hückel Hamiltonian. If the complete orthonormal system of $\mathbf{H}$, or set of functions that satisfy the equations (2)-(4), is known, then

$$
\begin{aligned}
& \mathbf{H}|\mathrm{n}\rangle=\epsilon_{\mathrm{n}}|\mathrm{n}\rangle, \\
& \langle\mathrm{n} \mid \mathrm{m}\rangle=\delta_{\mathrm{nm}}, \\
& \sum_{\mathrm{n}}|\mathrm{n}\rangle\langle\mathrm{n}|=\mathbf{1} .
\end{aligned}
$$

$\mathbf{G}(\mathrm{z})$ can then be expressed by the following equation:

$\mathbf{G}(\mathrm{z})=\sum_{\mathrm{n}} \frac{|\mathrm{n}\rangle\langle\mathrm{n}|}{\mathrm{z}-\epsilon_{\mathrm{n}}}$

If all of the systems to be investigated are composed of the same kinds of atoms, the Hückel Hamiltonian is simplified, as is shown in equation (6). It is simplified by taking the Coulomb integral as the energy origin and letting the energy unit be the resonance integral $(\boldsymbol{\beta})$.

$$
\mathbf{H}=\sum_{\mathrm{s}, \mathrm{t}}^{\prime}|\mathrm{s}\rangle\langle\mathrm{t}|
$$


In equation (6), the prime code attached to sum symbol means that addition is performed only between adjacent bonded atoms. Note that by selecting the resonance integral as the energy unit, the energy level of the positive value becomes stable. Furthermore, it is assumed that the base functions that are placed on each atom of the conjugated system compose the complete orthonormal system that satisfies the equations (2), (3), and (4).

Based on these assumptions, the diagonal elements $\left[\mathrm{L}_{n}(1)\right]$ of the propagator at the terminal atom position of the chain conjugated system shown in Fig. 2 are obtained by the following equations:

$\mathrm{L}_{\mathrm{n}}(1)=\frac{\mathrm{p}_{\mathrm{n}-1}(\mathrm{z})}{\mathrm{p}_{\mathrm{n}}(\mathrm{z})}$

$\mathrm{p}_{\mathrm{n}}(\mathrm{z})=\mathrm{zp} \mathrm{p}_{\mathrm{n}-1}(\mathrm{z})-\mathrm{p}_{\mathrm{n}-2}$

Since the Hückel Hamiltonian contains only one interaction (v), this study used the fact that the Dyson equation between the propagator in the perturbation system $[\mathbf{G}(\mathrm{z})]$ and that in the unperturbed system $\left(\mathbf{G}(\mathrm{z})^{0}\right)$ is expressed by the following equation:

$\mathbf{G}(\mathrm{z})=\mathbf{G}^{\mathbf{0}}(\mathrm{z})+\mathbf{G}^{\mathbf{0}}(\mathrm{z}) \mathbf{v} \mathbf{G}(\mathrm{z})$

Note that the values of $\mathrm{p}_{\mathrm{n}}(\mathrm{z})$ in equations (7) and (8) agree with the Hückel determinant. Some of the $\mathrm{p}_{\mathrm{n}}(\mathrm{z})$ values are listed below:

$\mathrm{p}_{1}(\mathrm{z})=\mathrm{z}$

$\mathrm{p}_{2}(\mathrm{z})=\mathrm{z}^{2}-1$

$\mathrm{p}_{3}(\mathrm{z})=\mathrm{z}^{3}-2 \mathrm{z}$

$\mathrm{p}_{4}(\mathrm{z})=\mathrm{z}^{4}-3 \mathrm{z}^{2}+1$

$p_{5}(z)=z^{5}-4 z^{3}+3 z$

$p_{6}(z)=z^{6}-5 z^{4}+6 z^{2}-1$.

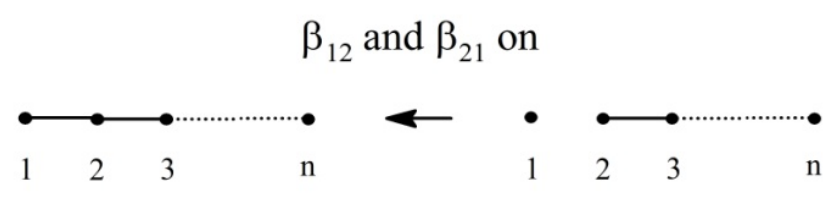

Perturbed chain Unperturbed chain

Fig. 2 Chain molecules and their unperturbed systems.

\section{§ I-2.3 Energy spectra}

To obtain the propagator of n-tridentene, system b in Fig. 3 was taken as the unperturbed system. Using equation (9), the orthogonal element $[G(0)]$ in the atom located at the center of the branching part of n-tridentene was obtained by equation (11), as follows: 
$\mathrm{G}(0)^{-1}=\frac{z p_{n}^{3}-3 p_{n}^{2} p_{n-1}}{p_{n}^{3}}$

The energy spectrum of the system is given by the pole of the propagator. Therefore, from equation (11), the energy spectrum of n-tridentene can be obtained from the solution of the following equation:

$z p_{n}^{3}-3 p_{n}^{2} p_{n-1}=0$

When the left side of equation (12) is specified, the following equations for the energy spectra of n-tridentene were obtained:

$\mathrm{n}=1$,

$z p_{1}^{3}-3 p_{1}^{2} p_{0}=p_{1}^{2}\left(z p_{1}-3 p_{0}\right)=z^{2}(z+\sqrt{3})(z-\sqrt{3})$,

$\mathrm{n}=2$,

$\mathrm{zp}_{2}^{3}-3 \mathrm{p}_{2}^{2} \mathrm{p}_{1}=\mathrm{p}_{2}^{2}\left(\mathrm{zp}_{2}-3 \mathrm{p}_{1}\right)=(\mathrm{z}+1)^{2}(\mathrm{z}-1)^{2} \mathrm{z}(\mathrm{z}+2)(\mathrm{z}-2)$,

$\mathrm{n}=3$,

$z p_{3}^{3}-3 p_{3}^{2} p_{2}=p_{3}^{2}\left(z p_{3}-3 p_{2}\right)$

$$
\begin{array}{r}
=z^{2}(z+\sqrt{2})^{2}(z-\sqrt{2})^{2}\left(z+\sqrt{\frac{5+\sqrt{13}}{2}}\right)\left(z-\sqrt{\frac{5+\sqrt{13}}{2}}\right) \\
\times\left(z+\sqrt{\frac{5-\sqrt{13}}{2}}\right)\left(z-\sqrt{\frac{5-\sqrt{13}}{2}}\right) .
\end{array}
$$

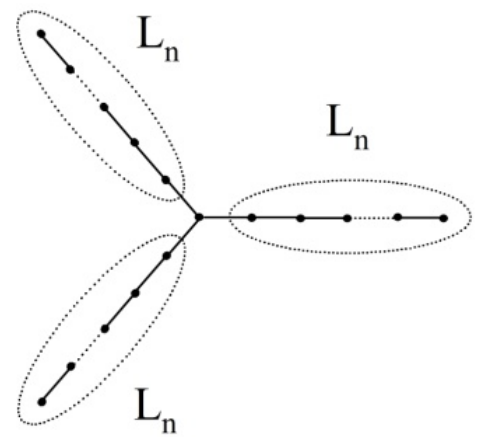

a

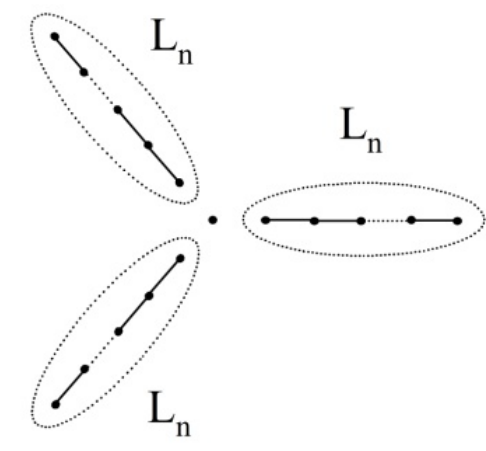

b

Fig. 3 The molecule n-Tridentene and its unperturbed system.

Here, it should be noted that equation (12) can be transformed into the following equation:

$p_{n}^{2}\left(z p_{n}-3 p_{n-1}\right)=0$

In addition, note that when the value of $\mathrm{z}$ that satisfies equation (14) is replaced with $\mathrm{z}=2 \cos \theta$, equation (15) is obtained. 


$$
\begin{aligned}
& p_{n}(z)=0, \\
& \theta_{r}=\frac{\pi r}{n+1}, r= \pm 1, \pm 2, \pm 3, \cdots, \pm n
\end{aligned}
$$
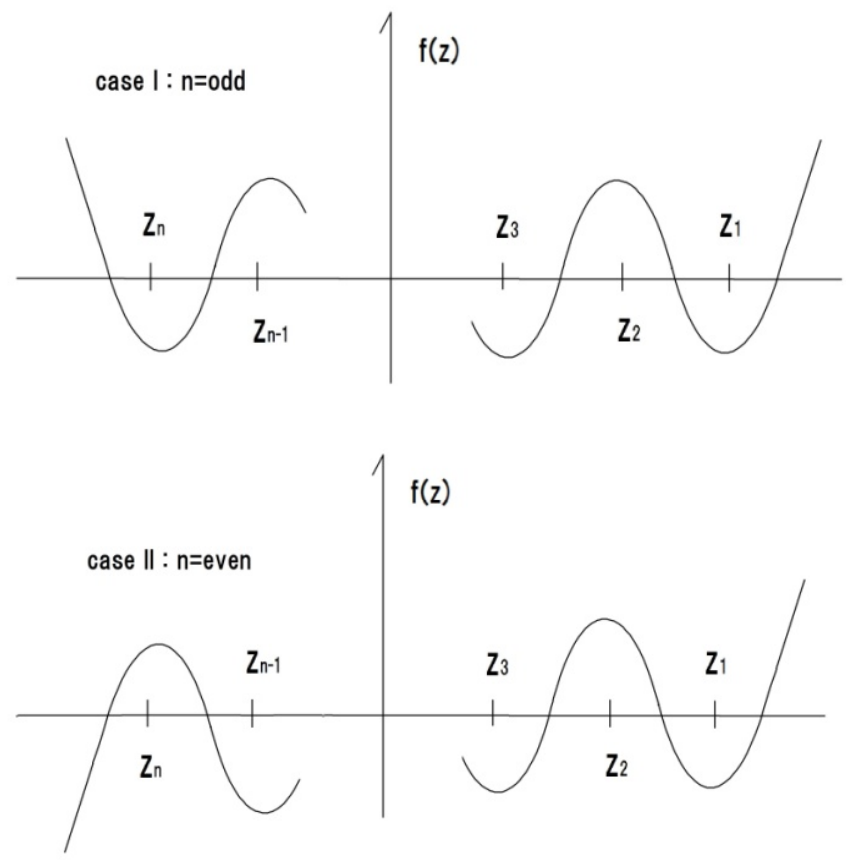

\section{Fig. 4 The sign of the function $\mathrm{f}(\mathrm{z})$.}

Case I: $\mathbf{z} \rightarrow \pm \infty, \mathbf{f}(\mathbf{z}) \rightarrow+\infty$; Case II: $\mathbf{z} \rightarrow \pm \infty, \mathbf{f}(\mathbf{z}) \rightarrow \pm \infty$.

Furthermore, when the value of $\theta_{\mathrm{r}}$ from equation (15) is substituted inside the parentheses on the left side of equation (13), the following equation is obtained:

$z p_{n}-3 p_{n-1}=3(-1)^{r} \sin \frac{\pi r}{n+1} \neq 0$

Therefore, in the energy levels of n-tridentene, there are 2n double degenerated levels given by equation (15) and $n+1$ levels without degeneracy.

In addition, considering that the $n+1$ levels without degeneracy are given by the intersection between the functions,

$f(z)=z p_{n}(z)-3 p_{n-1}(z)$

is defined by the left side of equation (16) and the z-axis, and the plus-minus sign of $\mathrm{f}(\mathrm{z})$ is investigated using the graph shown in Fig. 4. The results indicate that n-tridentene has an energy spectrum similar to the one shown in Fig. 5.

In other words, among the double degenerated energy levels, the sign of $f(z)$ is negative at the most stable $\mathrm{z}_{1}$, and $\mathrm{f}(\mathrm{z})$ diverges to $+\infty$ when $\mathrm{z}$ becomes $+\infty$. Therefore, since $\mathrm{f}(\mathrm{z})$ crosses the $\mathrm{z}$-axis on the low energy side of $\mathrm{z}_{1}$, the minimum value of the energy spectrum for $n$ tridentene does not have degeneracy. Furthermore, since the plus-minus sign of $f(z)$ reverses between two adjacent $\mathrm{z}_{\mathrm{r}}$ and $\mathrm{z}_{\mathrm{r}+1}$, a double degenerated level and a level without degeneracy alternatively appear. 


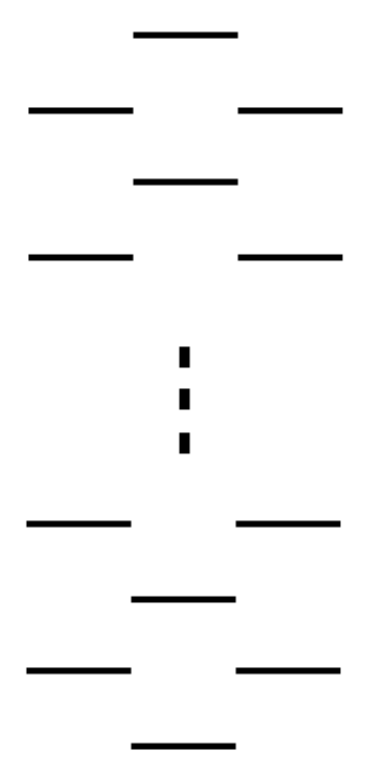

Fig. 5 Energy spectrum of n-tridentene.

\section{§ I-2.4 Magic number}

As a condition necessary for the energetic stabilization of n-tridentene, a condition is assumed wherein the $\pi$-electron system forms a closed shell. From the energy spectrum shown in Fig. 5, the m-th level from the bottom in n-tridentene is filled with $3+(-1)^{\mathrm{m}}$ electrons. Therefore, the magic number $\mathrm{N}$ can be obtained by summing the number of electrons that occupy up to the m-th level from the bottom, as is shown in the following equation:

$N=2,6,8,12, \cdots, \leq 6 n+2$

The magic number shown in equation (18) is generally given by the following equation:

$\mathrm{N}=3 \mathrm{n}-\frac{1-(-1)^{\mathrm{n}}}{2}, \mathrm{n}=1,2,3, \ldots$

Since the number of Hückel molecular orbitals coincides with that of the base functions of the system to be considered, the upper limit is identical to twice the $3 n+1$ base functions in the magic number of each n-tridentene molecule, as shown in equation (18).

To investigate the validity of the magic number obtained in this study, the relationship between the energetical stabilization and the number of $\pi$ electrons for four kinds of tridentene systems are shown in Fig. 6. Each system was investigated within the same range of the Hückel approximation discussed thus far. The results are summarized in Table 1. 
<smiles>CC(C)C</smiles>

1-tridentene<smiles>CCCC(CCC)CCC</smiles>

3-tridentene<smiles>CCC(CC)CC</smiles>

2-tridentene

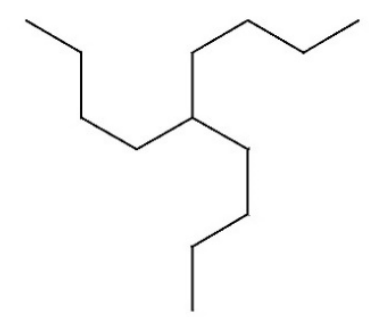

4-tridentene

Fig. 6 Several systems that were examined in this study.

Here, the standard of the energetical stabilization is set as a straight chain conjugated system. The reason that a straight-chain conjugated system is used as a reference system to estimate the energetical stabilization in Y-aromatic compounds is as follows: in the unperturbed system of tridentene (shown in Fig. 3b), the structure where all three $L_{n}$ are bonded to the atom located at the branching position corresponds to tridentene. Conversely, the structure where a single $\mathrm{L}_{n}$ is bonded to the atom located at the terminal end of the other $L_{n}$ (not to the atom located at the branching position) corresponds to the straight chain conjugated system. Note that since both n-tridentene and the chain conjugated system are alternate systems, the energy levels form a pair structure. Therefore, at the maximum number of electrons that each system can possess, the energy of the $\pi$ electrons in each system becomes zero, as in the case without $\pi$ electrons. For this reason, these cases are not good subjects for investigating the effectiveness of the magic number.

Table 1 Magic number and energy stabilization of $\mathbf{n}$-tridentene. The shaded columns are those that include a magic number.

\begin{tabular}{|l|l|l|}
\hline Species & $\mathrm{N}$ & $\Delta \mathrm{E}$ \\
\hline \multirow{4}{*}{ 1-tridentene } & 2 & 0.2280 \\
\cline { 2 - 3 } & 4 & -1.0080 \\
\cline { 2 - 3 } & 6 & 0.2280 \\
\cline { 2 - 3 } 2-tridentene & 8 & 0.0000 \\
\hline \multirow{5}{*}{ 3-tridentene } & 2 & 0.3045 \\
\cline { 2 - 3 } & 4 & -0.5239 \\
\cline { 2 - 3 } & 6 & -0.0547 \\
\cline { 2 - 3 } & 8 & -0.0547 \\
\cline { 2 - 3 } & 10 & -0.5239 \\
\cline { 2 - 3 } & 12 & 0.3045 \\
\cline { 2 - 3 } & 14 & 0.0000 \\
\hline & 6 & 0.3107 \\
\hline
\end{tabular}




\begin{tabular}{|l|l|l|}
\hline \multirow{5}{*}{} & 8 & -0.0086 \\
\cline { 2 - 3 } & 10 & -0.5779 \\
\cline { 2 - 3 } & 12 & -0.0086 \\
\cline { 2 - 3 } & 14 & -0.0169 \\
\cline { 2 - 3 } & 16 & -0.2259 \\
\cline { 2 - 3 } & 18 & 0.3107 \\
\cline { 2 - 3 } & 20 & 0.0000 \\
\hline \multirow{5}{*}{ 4-tridentene } & 2 & 0.3023 \\
\cline { 2 - 3 } & 4 & -0.0655 \\
\hline & 6 & 0.0432 \\
\cline { 2 - 3 } & 8 & 0.0678 \\
\cline { 2 - 3 } & 10 & -0.4316 \\
\cline { 2 - 3 } & 12 & -0.0857 \\
\cline { 2 - 3 } & 14 & -0.0857 \\
\cline { 2 - 3 } & 16 & -0.4316 \\
\cline { 2 - 3 } & 18 & 0.0678 \\
\cline { 2 - 3 } & 20 & 0.0432 \\
\cline { 2 - 3 } & 22 & -0.0655 \\
\cline { 2 - 3 } & 24 & 0.3023 \\
\cline { 2 - 3 } & 26 & \\
\hline
\end{tabular}

As is apparent from the shaded columns in Table 1, where the number of electrons corresponding to the magic number is shown, the magic number did not completely agree with the tendency of the energetical stability. However, for all four kinds of tridentene, a system containing the same number of electrons as the magic number was energetically stabilized or destabilized when compared with the chain conjugated system. However, even when destabilization is generated in the system, the degree of the destabilization was small compared with the cases containing an electron number other than the magic number.

\section{§ I-3 Conclusion of this section}

In this study, n-tridentene has been proposed as a system corresponding to annulene in Yaromatic compounds. The energy spectra of the $\pi$ electron system for n-tridentene were investigated by the normal method within the Hückel approximation. By setting the condition where the energy levels form a closed shell structure, the magic number for Y-aromaticity was derived. Under the Hückel approximation condition, some stabilization energies for ntridentene were obtained by utilizing a straight-chain conjugated system as a reference system. In addition, the validity of the magic numbers was investigated. The results indicated that the agreement between the magic numbers and the energetical stabilization was incomplete. However, in a system containing the same number of electrons as the magic number, even when energetical destabilization is generated, the degree of the destabilization was extremely small compared with the cases containing an electron number other than the magic number. In a cyclic conjugated system (i.e., annulene), even though it is not considered fully appropriate to utilize a straight-chain conjugated system as the standard for evaluating the stabilization energy $[10,11]$, the magic numbers obtained in the present study for n-tridentene are considered satisfactory in general. 
<smiles>CC(C)C(C)C(C)C(C)CSC(C)C(C)C(C)C(C)C</smiles>

Fig. 7 Comb-type $\pi$-electron conjugated compounds.

Future studies will investigate whether n-tridentene ions with the magic number of electrons can be synthesized by the quantum chemical calculation method with a higher degree of approximation. At the same time, the reference systems for defining the delocalization energy originating from only Y-shaped structures corresponding to the topological resonance energy in cyclic aromatic compounds will be investigated. Due to the results of these studies, it is expected that practical research of Y-aromatic compounds will begin. To extract the delocalization energy specific to Y-shaped structures, an investigation on the existence of the energetical stabilization for compounds with a series of Y-shaped structures (as is shown in Fig. 7) is ongoing.

\section{References for Section I}

[1] P. Gund, J. Chem. Educ., 49, 100-103(1972).

[2] L. Grajcar, G. Berthier, J. Faure, J.-P. Fleury, Theor. Chim. Acta, 71, 299-304(1987).

[3] Ohwada, T., Kagawa, H., Ichikawa, H., Bull. Chem. Soc. Jpn., 70, 2411-2415(1997).

[4] T. P. Radhakrishnan, I. Agranat, J. Org. Chem., 66, 3215-3219(2001).

[5] A. Dworkin, R. Naumann, C. Seigfred, J. M. Karty, Y. Mo, J. Org. Chem., 70, 76057616(2005).

[6] I. J. Binoy, C. James, J. I. Hubert, V. S. Jayakumar, J. Mol. Struct., 784, 32-46(2006).

[7] I. Rozas, G. S. Sanz, I. Alkorta, J. Elguero, J. Phys. Org. Chem., 26, 378-385(2013).

[8] I. Agranat, A. Skancke, J. Am. Chem. Soc., 107, 867-871(1985).

[9] S. Huzinaga, “Molecular Orbital Theory”, Iwanami Shoten (1980), pp.330-334. in Japanese. [10] J. Aihara, J. Am. Chem. Soc., 98, 2750-2758(1976).

[11] J. Aihara, Netsu Sokutei, 12, 61-72 (1985). in Japanese.

[12] S. Aono, K. Nishikawa, Bull. Chem. Soc. Jpn., 53, 3418-3423(1980).

[13] S. Aono, "Electronic states of molecules”, ed. by J. Higuchi, KYORITSU SHUPPAN CO., LTD (1986), pp.143-154. in Japanese.

[14] H. Hosoya, “Topological Index”, NIPPON HYORON SHA CO., LTD. (2012), pp.54-56. in Japanese.

\section{§ II Research on Magic Number of Y-Aromaticity using Semi-Empirical Molecular- Orbital Method}

\section{$\S$ II-1 Introduction}

To explain the strong basic character of guanidine, in the concept of Y-aromaticity, the branched structure of the $\pi$-electron conjugated system is considered to ensure the energetic stabilization of the system [1]. This new concept of aromaticity, which does not consider the existence of a cyclic $\pi$-electron conjugated system essential in the conventional concept of aromaticity, is a fascinating possibility of a working hypothesis for molecular design, and till now, it has been the subject of numerous studies [2-7]. However, because a rule corresponding to the $4 n+2$ rule [8], which predicts the number of $\pi$-electrons for aromaticity in annulene, the simplest cyclic $\pi$-electron conjugated system, has not been known for Y-aromatic systems, 
systematic studies, both theoretical and experimental, have not been feasible in this situation.

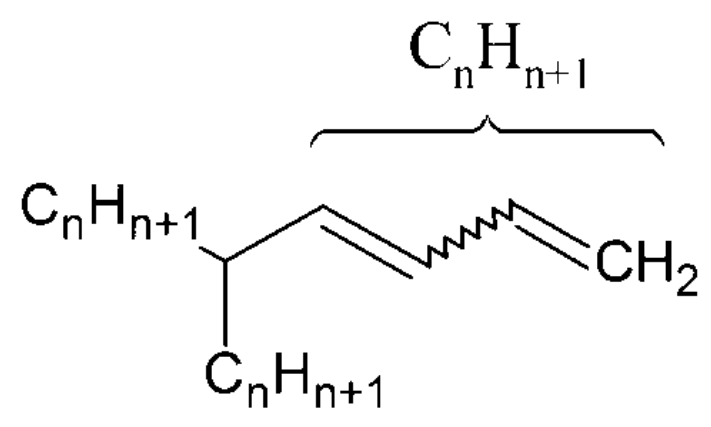

Fig. 1 n-Tridentene.

Therefore, in the previous section, the author proposed n-tridentene shown in Fig. 1 as a molecule corresponding to annulene in Y-aromaticity and derived the magic number in Yaromaticity shown in equation (1), assuming that energetic stabilization occurs when this $\pi$ electron conjugated system forms a closed shell [9].

In this section, the effectiveness of the magic number reported in the previous section will be examined using the semi-empirical molecular-orbital method [10,11], which is commonly used in organic synthesis as well and has proven to be very reliability. Moreover, Y-aromatic compounds that can serve as specific synthetic targets will also be searched.

$\mathrm{N}=3 \mathrm{n}-\frac{1-(-1)^{\mathrm{n}}}{2}, \mathrm{n}=1,2,3, \cdots$

\section{§ II-2 Calculation method and model compounds}

\section{$\S$ II-2.1 Calculation method}

The structural optimization of the ground state of the model compound was performed using the PM5 method [12,13] of SCIGRESS MO Compact ver.1.0.0 Standard (Fujitsu) to determine the heat of formation, obtain MO data, and clarify the optimized structure.

\section{§ II-2.2 Model compounds}

As model compounds, $n$-tridentenes $(n=1 \sim 6)$ shown in Fig. 1 were considered. These molecules have a structure in which the three methylene groups of trimethylenemethane are each replaced by a chain conjugate system comprising $\mathrm{n}$ carbon atoms. This chain conjugate system can be arranged in various configurations, but the purpose of this paper is to verify the magic number obtained at the level of the Hückel approximation. Tridentenes with radially extended chain conjugates were adopted as the model system.

Furthermore, in the charged state, which is expected to comprise the number of $\pi$-electrons corresponding to the magic number, because a planar or close to the planar structure was found as the optimized structure, the heat of formation and MO data used for the verification of the magic number were calculated with the planar structure fixed, including the reference system.

\section{§ II-3 Results and Discussion}

The heat of formation and HOMO-LUMO gap values for the six types of $\mathrm{n}$-tridentenes $(\mathrm{n}=$ 1 6) are summarized in Table 1. 
Table 1 Quantum-chemical data of $\mathbf{n}$-Tridentene and a reference system calculated using a semi-empirical molecular orbital method.

\begin{tabular}{|l|l|l|l|l|}
\hline $\mathbf{N}$ & $\mathbf{M}$ & Species & $\Delta \mathbf{H}_{\mathbf{f}}$ & $\Delta \boldsymbol{\varepsilon}_{\mathbf{H L}}$ \\
\hline 4 & 4 & $\mathrm{C}_{4} \mathrm{H}_{6}$ & 28.73771 & 9.9457 \\
\hline 4 & 4 & 1-tridentene & 109.20234 & 4.7517 \\
\hline 4 & 2 & $\mathrm{C}_{4} \mathrm{H}_{6}{ }^{2+}$ & 572.58785 & 8.9205 \\
\hline 4 & $2^{*}$ & 1-tridentene $^{2+}$ & 557.93776 & 11.0108 \\
\hline 4 & 6 & $\mathrm{C}_{4} \mathrm{H}_{6}{ }^{2-}$ & 176.38200 & 8.2345 \\
\hline 4 & $6^{*}$ & 1-tridentene $^{2-}$ & 165.29564 & 10.2935 \\
\hline 7 & 7 & $\mathrm{C}_{7} \mathrm{H}_{9}$ & 62.78176 & 0.0000 \\
\hline 7 & 7 & 2-tridentene & 64.56472 & 0.0000 \\
\hline 7 & 6 & $\mathrm{C}_{7} \mathrm{H}_{9}{ }^{+}$ & 223.98636 & 7.2893 \\
\hline 7 & $6^{*}$ & 2-tridentene $^{+}$ & 227.53426 & 8.4185 \\
\hline 7 & 8 & $\mathrm{C}_{7} \mathrm{H}_{9}{ }^{-}$ & 26.37724 & 7.1055 \\
\hline 7 & $8^{*}$ & 2-tridentene $^{-}$ & 29.44415 & 8.0759 \\
\hline 10 & 10 & $\mathrm{C}_{10} \mathrm{H}_{12}$ & 69.21545 & 7.8910 \\
\hline 10 & 10 & 3-tridentene $^{2}$ & 137.72989 & 3.7115 \\
\hline 10 & 8 & $\mathrm{C}_{10} \mathrm{H}_{12}{ }^{2+}$ & 496.74026 & 6.8789 \\
\hline 10 & $8^{*}$ & 3-tridentene $^{2+}$ & 508.82617 & 7.4369 \\
\hline 10 & 12 & $\mathrm{C}_{10} \mathrm{H}_{12}{ }^{2-}$ & 98.71819 & 6.7291 \\
\hline 10 & $12^{*}$ & 3-tridentene $^{2-}$ & 110.60365 & 7.2524 \\
\hline 13 & 13 & $\mathrm{C}_{13} \mathrm{H}_{15}$ & 103.83481 & 0.0000 \\
\hline 13 & 13 & 4-tridentene & 105.21851 & 0.0000 \\
\hline 13 & 12 & $\mathrm{C}_{13} \mathrm{H}_{15}{ }^{+}$ & 251.32290 & 5.9174 \\
\hline 13 & $12^{*}$ & 4-tridentene $^{+}$ & 253.46107 & 6.8934 \\
\hline 13 & 14 & $\mathrm{C}_{13} \mathrm{H}_{15}{ }^{-}$ & 52.64671 & 5.9037 \\
\hline 13 & $14^{*}$ & 4-tridentene $^{-}$ & 54.31928 & 6.7545 \\
\hline 16 & 16 & $\mathrm{C}_{16} \mathrm{H}_{18}$ & 109.61430 & 7.3227 \\
\hline 16 & 16 & 5-tridentene & 173.66287 & 3.3115 \\
\hline 16 & 14 & $\mathrm{C}_{16} \mathrm{H}_{18}{ }^{2+}$ & 491.82161 & 6.1241 \\
\hline 16 & $14^{*}$ & 5-tridentene $^{2+}$ & 507.91719 & 6.2101 \\
\hline 16 & 18 & $\mathrm{C}_{16} \mathrm{H}_{18}{ }^{2-}$ & 93.18828 & 6.0937 \\
\hline 16 & $18^{*}$ & 5-tridentene $^{2-}$ & 108.32751 & 6.1592 \\
\hline 19 & 19 & $\mathrm{C}_{19} \mathrm{H}_{21}$ & 144.43086 & 0.0000 \\
\hline 19 & 19 & 6-tridentene & 146.01802 & 0.0000 \\
\hline 19 & 18 & $\mathrm{C}_{19} \mathrm{H}_{21}{ }^{+}$ & 287.34579 & 5.3219 \\
\hline 19 & $18^{*}$ & 6-tridentene $^{+}$ & 287.69580 & 6.1313 \\
\hline 19 & 20 & $\mathrm{C}_{19} \mathrm{H}_{21}{ }^{-}$ & 87.92006 & 5.3606 \\
\hline & 6-tridentene $^{-}$ & 87.77798 & 6.0912 \\
\hline
\end{tabular}

$\mathrm{N}$ : number of carbon atoms, $M$ : number of $\pi$ electrons, $M^{*}$ : magic number, $\triangle \mathbf{H}_{\mathrm{f}}$ : Heat of Formation ( $\mathrm{kcal} / \mathrm{mol}$ ), $\triangle \varepsilon_{\mathrm{HL}}:$ HOMO-LUMO gap ( $\mathrm{eV}$ ).

Further, as a basis for energetic stabilization [9], the results of the calculation of chainconjugated systems with the same number of carbon atoms and $\pi$-electrons as each tridentene using the same method as for n-tridentenes are similarly shown in Table 1. However, the 
charged states of the n-tridentenes to be calculated were limited to the case in which each ntridentene has the same number of $\pi$-electrons as the magic number and the absolute value of the charge number to the minimum case.

For example, in the case of 3-tridentene, $10 \pi$-electrons exist in the neutral system. As the magic numbers closest to this value are 8 and 12, by performing calculations for 3-tridentene and its reference system $\mathrm{C}_{10} \mathrm{H}_{12}$ in neutral and \pm 2 charged states, respectively, it was found that when the magic number and the $\pi$-electron number coincided, the degeneration pattern of the $\pi$-electron orbital of 3-tridentene was in conformity with that of the $\pi$-electron orbital according to the Hückel approximation (Table 2) [9], which was the basis when we proposed the magic number.

Table 2 Molecular-orbital energy of 3-Tridentene and its ions.

\begin{tabular}{|l|l|l|l|}
\hline & 3-tridentene & 3-tridentene & 3-tridentene $^{2-}$ \\
\hline $\boldsymbol{\varepsilon}_{\mathbf{1 0}}$ & 3.3507 & -5.8602 & 11.7317 \\
\hline $\boldsymbol{\varepsilon}_{\mathbf{9}}$ & 2.0033 & -6.4914 & 10.1872 \\
\hline $\boldsymbol{\varepsilon}_{\mathbf{8}}$ & 1.4173 & -6.4915 & 10.1872 \\
\hline $\boldsymbol{\varepsilon}_{\mathbf{7}}$ & 0.5649 & -7.9243 & 8.5618 \\
\hline $\boldsymbol{\varepsilon}_{\mathbf{6}}$ & -2.4855 & -9.9756 & 1.3094 \\
\hline $\boldsymbol{\varepsilon}_{\mathbf{5}}$ & -6.1970 & -9.9757 & 1.3094 \\
\hline $\boldsymbol{\varepsilon}_{\mathbf{4}}$ & -9.2426 & -17.4126 & -1.0253 \\
\hline $\boldsymbol{\varepsilon}_{\mathbf{3}}$ & -10.8241 & -19.4964 & -2.9227 \\
\hline $\boldsymbol{\varepsilon}_{\mathbf{2}}$ & -11.6174 & -19.4965 & -2.9227 \\
\hline $\boldsymbol{\varepsilon}_{\mathbf{1}}$ & -13.0228 & -21.7910 & -4.2801 \\
\hline
\end{tabular}

Unit of $\varepsilon_{i}$ is $\mathbf{e V}$.

Searching for a system that can be expected to be energetically stable by the comparison of the heat of formation values highlighted that the only system that could be suggested to be energetically stable is the anion of 6-tridentene (Fig. 2), which is shaded in the last row of Table 1, except for 1-tridentene, which is the model system of guanidine. Notably, the magnitude of bond alternation in the 6-tridentene arm parts from a to $\mathbf{f}$ was the smallest for the anion (Table 3).

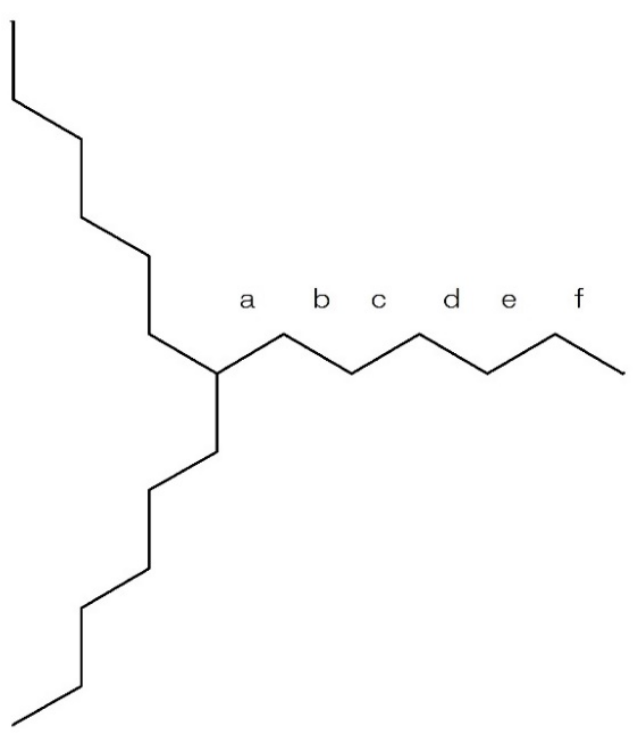

Fig. 2 6-Tridentene and its chemical bonding. 
Next, upon examining the size of the HOMO-LUMO gap, as shown by the shading in Table 1 , the size of the HOMO-LUMO gap of tridentene ions containing the same number of $\pi$ electrons as the magic number in all the systems exceeded that of the corresponding reference systems. The size of the HOMO-LUMO gap can be related to the magnitude of the reactivity [14], and the tendency observed in Table 1 for the HOMO-LUMO gap can be considered to indicate a decrease in reactivity of tridentene ions containing the same number of $\pi$ electrons as the magic number.

Table 3 Bond lengths of the 6-Tridentene arm portion.

\begin{tabular}{|l|l|l|l|}
\hline & neutral & anion & cation \\
\hline$l_{\mathrm{a}}$ & 1.320 & 1.324 & 1.324 \\
\hline $\mathrm{l}_{\mathrm{b}}$ & 1.457 & 1.447 & 1.451 \\
\hline $\mathrm{l}_{\mathrm{c}}$ & 1.333 & 1.341 & 1.343 \\
\hline $\mathrm{l}_{\mathrm{d}}$ & 1.451 & 1.433 & 1.435 \\
\hline $\mathrm{l}_{\mathrm{e}}$ & 1.344 & 1.353 & 1.355 \\
\hline $\mathrm{l}_{\mathrm{f}}$ & 1.431 & 1.421 & 1.425 \\
\hline$\Sigma_{\mathrm{x}}\left(\mathrm{l}_{\mathrm{x}} / \mathrm{l}_{\mathrm{a}}\right)$ & 6.315 & 6.283 & 6.294 \\
\hline
\end{tabular}

$l_{x:}$ Length of the bond $x(\AA)$.

\section{§ II-4 Conclusion of this section}

The above results led to the following two conclusions:

a: The 6-tridentene anion is a system in which both energetic and reactive stabilization can be anticipated.

b: For tridentene ions containing the same number of $\pi$-electrons as the magic number, the value of the HOMO-LUMO gap is larger than that of the corresponding reference system.

These facts suggest that the magic number proposed in the previous section is a value that predicts not energetical but reaction kinetical stabilization. Considering the low chemical reactivity of noble gas elements forming closed shell, it can be assumed that the magic number of n-tridentene is required as a necessary condition for the formation of a closed shell, predicting a decrease in reactivity.

\section{Acknowledgments}

We would like to express our gratitude to Fujitsu Kyushu Systems Ltd. for providing us with the literature to carry out this study.

\section{References and Notes for Section II}

[1] P. Gund, J. Chem. Educ., 49, 100-103(1972).

[2] L. Grajcar, G. Berthier, J. Faure, J.-P. Fleury, Theor. Chim. Acta, 71, 299-304(1987).

[3] T. Ohwada, H. Kagawa, H. Ichikawa, Bull. Chem. Soc. Jpn., 70, 2411-2415(1977).

[4] T. P. Radhakrishnan, I. Agranat, J. Org. Chem., 66, 3215-3219(2001).

[5] A. Dworkin, R. Naumann, C. Seigfred, J. M. Karty, Y. Mo, J. Org. Chem., 70, 7605-7616(2005).

[6] I. J. Binoy, C. James, J. I. Hubert, V. S. Jayakumar, J. Mol. Struct., 784, 32-46(2006).

[7] I. Rozas, G. S. Sanz, I. Alkarta, J. Elguero, J. Phys. Org. Chem., 26, 378-385(2013).

[8] M. Sainsbury, “Aromatic Chemistry”, Oxford University Press Inc., New York (1992), pp.37.

[9] T. Ohmae, Journal of Computer Aided Chemistry, 19, 19-25(2018). in Japanese.

[10] K. Tanabe, K. Hori, "Molecular Orbital Method for Organic Chemical Reactions", Maruzen Publishing Co., Ltd., Tokyo (1997), pp.1-19. in Japanese.

[11] K. Somekawa, "Molecular Orbital Calculation of Organic Molecules and The 
Applications”, Kyushu University Press (2013), pp.79-92.

[12] J. J. P. Stewart, J. Comput. Chem., 10, 221-264(1989).

[13] J. J. P. Stewart, “MOPAC2002 Manual”, Fujitsu Limited, Tokyo (2001).

[14] V. I. Minkin, M. N. Glukhovtsev, B. Y. Simkin, “Aromticity and Antiaromaticity”, John Wiley \& Sons, Inc., New York (1994), pp.80-85.

\section{§ III Quantum Chemical Studies on Typhoon Tridentene and Cyclone Tridentene § III-1 Introduction}

The proposed n-tridentene (Fig. 1) as a candidate for a typical Y-aromatic compound has a structure in which the three methylenes of trimethylenemethane are replaced by a linear $\pi$ electron conjugated system, consisting of $n$ carbon atoms each [1].

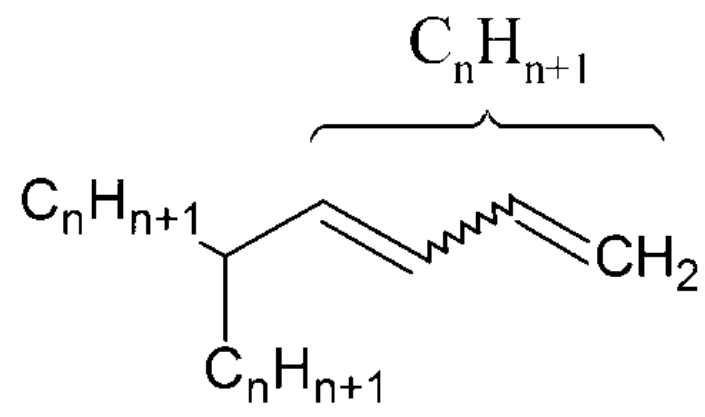

Fig. 1 n-Tridentene.

Investigations based on quantum chemical techniques [2] have demonstrated that the magic number of Y-aromaticity, which is generally derived by imposing a closed-shell condition [3] on the $\pi$-electron conjugated system of the whole compound, is suitable to predict the decrease in reactivity of the system in question. When performing molecular orbital calculations for verification, the optimized structure was restricted in a manner that all atoms of the three linear $\pi$-electron conjugated systems of n-tridentene were arranged radially in the same plane. The purpose was to minimize the interaction between $\pi$-electrons that are not adjacent by bonding and to keep consistency with the Hückel approximation [4] used to derive the magic number. However, if this compound is to be considered not only as a Y-aromatic compound but also as a candidate for functional molecular ions forming ionic liquids [5], various arrangements of the three linear $\pi$-electron conjugated systems constituting the entire system have to be examined.

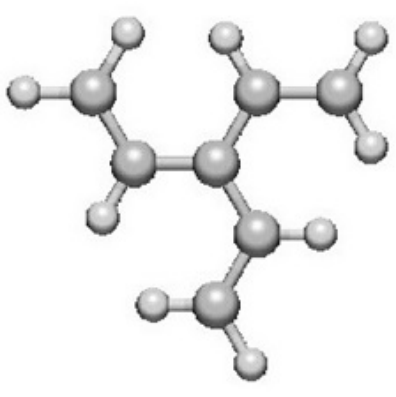

2-Tridentene

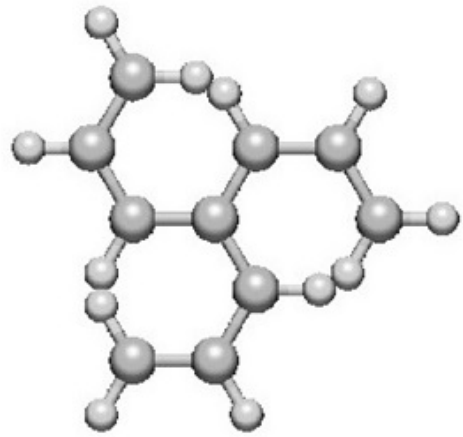

3-Tridentene

Fig. 2 Tridentene with atoms arranged in a typhoon configuration. 
This section reports the results of semiempirical molecular orbital studies of 2-tridentene and 3 -tridentene, which are linear $\pi$-electron conjugated systems arranged in a spiral configuration (Fig. 2). The initial structure of these systems was assumed to be planar, but nonplanar structures were also permitted at the time of structural optimization calculations.

\section{$\S$ III-2 Calculation method and model compounds \\ § III-2.1 Calculation method}

The structural optimization calculations of the model compounds were performed in the ground state using the PM5 method [6, 7] of SCIGRESS MO Compact ver. 1.0.0 Standard (Fujitsu). In addition to the information regarding the molecular structure, the heat of formation and MO data were obtained.

\section{§ III-2.2 Model compounds}

As model compounds, 2-tridentene and 3-tridentene were adopted, in which the linear conjugated system is arranged in a left-handed spiral (Fig. 2), and performed calculations related to ions and neutral molecules with the minimum absolute value of the charge state where the $\pi$-electron conjugated system of the entire system forms a closed shell. Here, the magic number reported in the first paper was used to predict the charged state, where each system forms a closed shell.

\section{§ III-3 Results and discussion}

\section{§ III-3.1 2-Tridentene}

The optimized structure of 2-tridentene was identified as a planar structure having $\mathrm{C}_{3} \mathrm{~h}$ symmetry for both the neutral molecule and \pm 1 -valent ion, in which the $\pi$-electron conjugated system forms a closed shell without distinction between right- and left-handed structures. The molecular structure and the charge distribution of the optimized 2-tridentene are shown in Table 1. The numbering of the atoms is shown in Fig. 3.

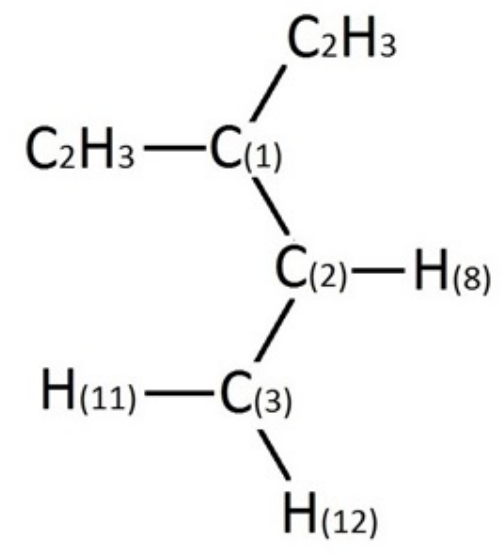

\section{Fig. 3 Numbering of atoms constituting 2-tridentene.}

As shown in Table 1, positive charge is localized on the cation at $\mathrm{C}(1)$, which is located at the center of the Y-shaped structure of 2-tridentene, while negative charge is localized on the anion. The reason is that, as shown in Fig. 4, the cation of 2-tridentene has a HOMO nodal plane that crosses $\mathrm{C}(1)$ and divides the molecule into two; whereas, the anion has a HOMO nodal plane that crosses $\mathrm{C}(2)$ and divides into two the molecule in the radial direction. However, there was no considerable regularity in the change in the amount and the sign of the charge as the carbon atoms were traced from $\mathrm{C}(1)$ to $\mathrm{C}(2), \mathrm{C}(3)$, and outward in the radial direction. 

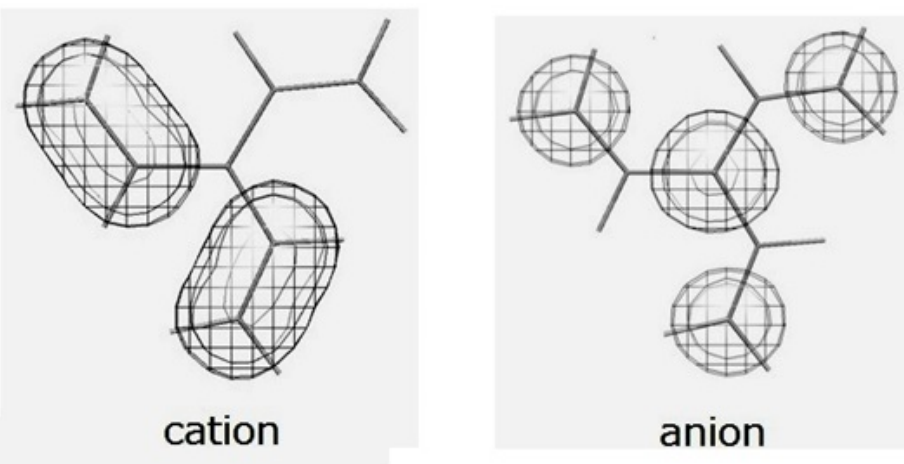

Fig. 4 Highest occupied molecular orbitals of 2-tridentene cation and anion.

Table 1 Structure of optimized 2-tridentene and charge distribution.

\begin{tabular}{|c|c|c|c|c|c|}
\hline \multicolumn{6}{|c|}{ Heat of Formation : $64.56472 \mathrm{kcal} / \mathrm{mol}$} \\
\hline Atom number: I & Bond length*, NA : I & Bond angle**, NB:NA:I & NA & NB & Atomic charge \\
\hline 1 & 0.000 & 0.000 & & & -0.041 \\
\hline 2 & 1.437 & 0.000 & 1 & & -0.126 \\
\hline 3 & 1.328 & 126.4 & 2 & 1 & -0.293 \\
\hline 8 & 1.100 & 116.0 & 2 & 1 & 0.146 \\
\hline 11 & 1.090 & 125.1 & 3 & 2 & 0.142 \\
\hline 12 & 1.092 & 121.1 & 3 & 2 & 0.144 \\
\hline \multicolumn{6}{|c|}{ Charge $:+1 \quad$ Heat of Formation $: 227.53462 \mathrm{kcal} / \mathrm{mol}$} \\
\hline Atom number: I & Bond length*, NA : I & Bond angle**, NB:NA:I & NA & NB & Atomic charge \\
\hline 1 & 0.000 & 0.000 & & & 0.404 \\
\hline 2 & 1.432 & 0.000 & 1 & & -0.344 \\
\hline 3 & 1.337 & 125.9 & 2 & 1 & -0.034 \\
\hline 8 & 1.105 & 117.0 & 2 & 1 & 0.209 \\
\hline 11 & 1.095 & 125.5 & 3 & 2 & 0.172 \\
\hline 12 & 1.098 & 120.4 & 3 & 2 & 0.195 \\
\hline \multicolumn{6}{|c|}{ Charge : -1 Heat of Formation : $29.44415 \mathrm{kcal} / \mathrm{mol}$} \\
\hline Atom number: I & Bond length*, NA : I & Bond angle**, NB:NA:I & NA & NB & Atomic charge \\
\hline 1 & 0.000 & 0.000 & & & -0.468 \\
\hline 2 & 1.424 & 0.000 & 1 & & 0.092 \\
\hline 3 & 1.335 & 128.9 & 2 & 1 & -0.558 \\
\hline 8 & 1.100 & 115.2 & 2 & 1 & 0.079 \\
\hline 11 & 1.086 & 124.6 & 3 & 2 & 0.114 \\
\hline 12 & 1.088 & 121.4 & 3 & 2 & 0.096 \\
\hline
\end{tabular}

*: Angstroms, **: Degrees. 


\section{§ III-3.2 3-Tridentene}

The neutral molecule of 3-tridentene could not be optimized in a Y-shaped structure. In contrast, the dianion of 3-tridentene, in which the $\pi$-electron conjugated system of the whole 3 tridentene molecule forms a closed shell, was optimized to a planar structure that has a $\mathrm{C}_{3} \mathrm{~h}$ symmetry. This indicates that, like in 2-tridentene, there is no distinction between right- and left-handed dianions in 3-tridentene. However, the optimized structure of the dication, in which the $\pi$-electron conjugated system of the whole molecule forms a closed shell as does the dianion, is a shallow bowl-shaped structure with C3 symmetry, in which the carbon skeleton has a depression with the depth of approximately $1.048 \AA$. This indicates that the 3-tridentene dication has a cyclone-type antipode with a spiral structure in the opposite direction to the typhoon type (Fig. 5). These calculation results suggest the possibility of controlling the charge state and the structure of 3-tridentene by suitable selection of the electronegativity of the counterion. Henceforth, the left-handed n-tridentene will be referred to as n-typhoon tridentene, and the reversely right-handed n-tridentene will be referred to as n-cyclone tridentene in a position with the convex side facing down.
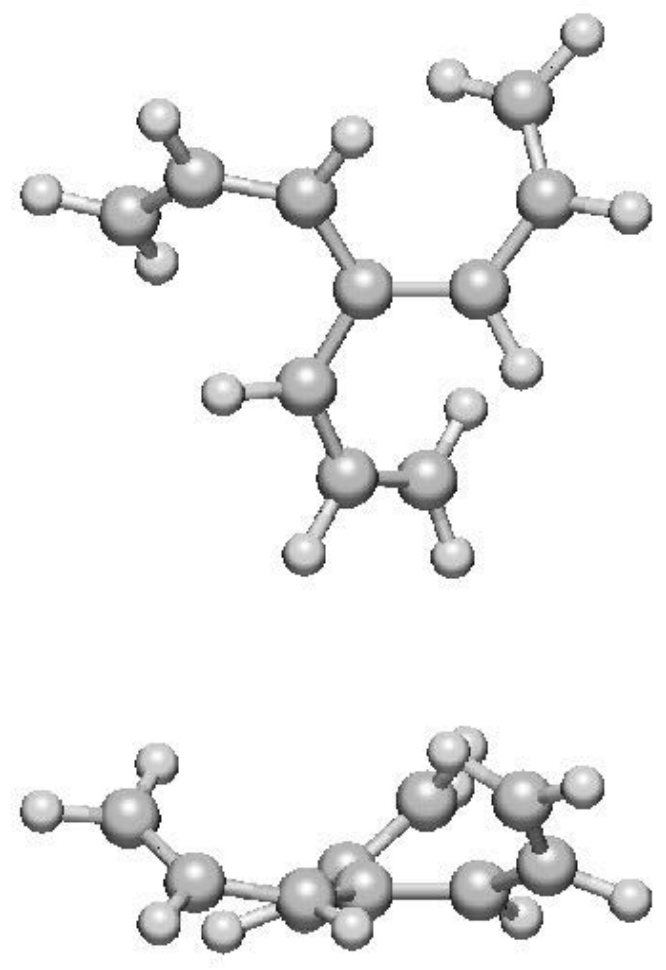

Fig. 5 Optimized structure of dication for typhoon-type 3-tridentene.

The molecular structure and the charge distribution of the optimized 3-tridentene are summarized in Table 2. The numbering of the atoms is shown in Fig. 6. As shown in Table 2, in the case of 3-tridentene, interesting results were obtained, namely, the charge of sign opposite to that of the whole molecule is localized at $\mathrm{C}(1)$, which is located at the center of the Y-shaped structure. The plausible reason is that, contrary to the case of the 2-tridentene ion, the HOMO of the dication in 3-tridentene divides the molecule in the radial direction, whereas the HOMO nodal plane of the dianion crosses $\mathrm{C}(1)$. Furthermore, the charge distribution of each ion shows regularly changing sign from $\mathrm{C}(1)$ to $\mathrm{C}(2), \mathrm{C}(3), \mathrm{C}(4)$, and in the outward radial direction. This regularly alternating charge distribution suggests the possibility of selective ionic bond formation between 3-typhoon tridentene and 3-cyclone tridentene, according to the symmetry of the counterion charge distribution. 


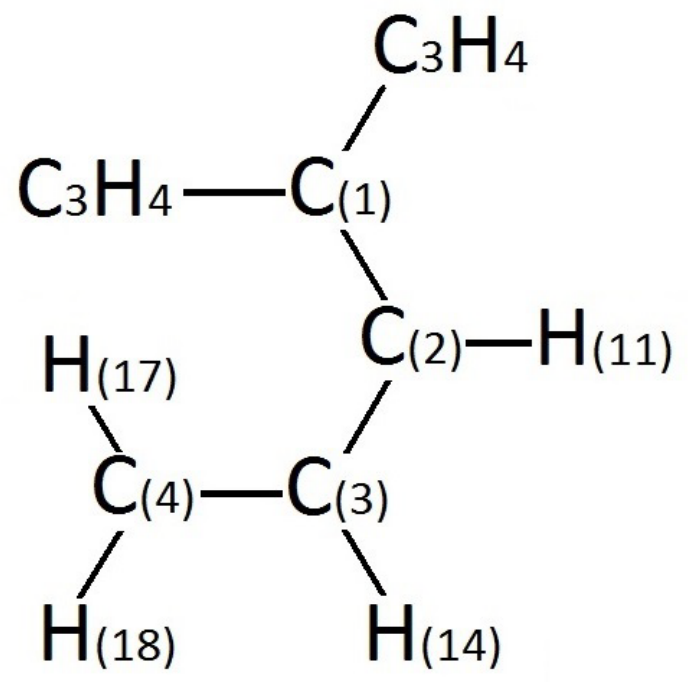

Fig. 6 Numbering of atoms constituting 3-tridentene.

Table 2 Structure of optimized 3-tridentene and charge distribution.

\begin{tabular}{|c|c|c|c|c|c|c|c|}
\hline \multicolumn{8}{|c|}{ Heat of Formation : $128.41922 \mathrm{kcal} / \mathrm{mol}$} \\
\hline $\begin{array}{l}\text { Atom } \\
\text { number: I }\end{array}$ & $\begin{array}{l}\text { Bond length* } \\
\text { NA : I }\end{array}$ & $\begin{array}{l}\text { Bond angle** } \\
\text { NB : NA: I }\end{array}$ & Twist angle** & NA & NB & NC & Atomic charge \\
\hline 1 & 0.000 & 0.000 & 0.000 & & & & 0.428 \\
\hline 2 & 1.415 & 0.000 & 0.000 & 1 & & & -0.596 \\
\hline 3 & 1.387 & 133.3 & 0.000 & 2 & 1 & & 0.146 \\
\hline 4 & 1.347 & 135.6 & 0.000 & 3 & 2 & 1 & -0.669 \\
\hline 11 & 1.097 & 114.7 & 180.0 & 2 & 1 & 3 & 0.125 \\
\hline 14 & 1.109 & 111.4 & -180.0 & 3 & 2 & 1 & -0.000 \\
\hline 17 & 1.085 & 123.8 & 0.000 & 4 & 3 & 2 & 0.125 \\
\hline 18 & 1.088 & 121.3 & 180.0 & 4 & 3 & 2 & 0.060 \\
\hline \multicolumn{8}{|c|}{ Charge : +2 Symmetry : C3 } \\
\hline $\begin{array}{l}\text { Atom } \\
\text { number:I }\end{array}$ & $\begin{array}{l}\text { Bond length* } \\
\text { NA : I }\end{array}$ & $\begin{array}{l}\text { Bond angle** } \\
\text { NB : NA : I }\end{array}$ & Twist angle** & NA & NB & NC & Atomic charge \\
\hline 1 & 0.000 & 0.000 & 0.000 & & & & -0.398 \\
\hline 2 & 1.418 & 0.000 & 0.000 & 1 & & & 0.238 \\
\hline 3 & 1.398 & 126.3 & 0.000 & 2 & 1 & & -0.355 \\
\hline 4 & 1.350 & 127.1 & -27.14 & 3 & 2 & 1 & 0.021 \\
\hline 11 & 1.109 & 117.8 & 175.9 & 2 & 1 & 3 & 0.215 \\
\hline 14 & 1.115 & 115.0 & 156.8 & 3 & 2 & 1 & 0.272 \\
\hline 17 & 1.096 & 124.6 & -5.453 & 4 & 3 & 2 & 0.173 \\
\hline 18 & 1.104 & 120.6 & 179.5 & 4 & 3 & 2 & 0.237 \\
\hline
\end{tabular}




\begin{tabular}{|l|l|l|l|l|l|l|l|}
\hline \multicolumn{6}{|l|}{ Charge : +2} & Symmetry : C3h Heat of Formation : 529.36920kcal/mol \\
\hline $\begin{array}{l}\text { Atom } \\
\text { number:I }\end{array}$ & $\begin{array}{l}\text { Bond length* } \\
\text { NA : I }\end{array}$ & $\begin{array}{l}\text { Bond angle** } \\
\text { NB : NA : I }\end{array}$ & Twist angle** & NA & NB & NC & Atomic charge \\
\hline 1 & 0.000 & 0.000 & 0.000 & & & & -0.363 \\
\hline 2 & 1.418 & 0.000 & 0.000 & 1 & & & 0.248 \\
\hline 3 & 1.396 & 134.4 & 0.000 & 2 & 1 & & -0.363 \\
\hline 4 & 1.350 & 132.6 & 0.000 & 3 & 2 & 1 & 0.060 \\
\hline 11 & 1.108 & 115.0 & -180.0 & 2 & 1 & 3 & 0.187 \\
\hline 14 & 1.116 & 112.5 & -180. & 3 & 2 & 1 & 0.253 \\
\hline 17 & 1.096 & 126.3 & 0.000 & 4 & 3 & 2 & 0.167 \\
\hline 18 & 1.104 & 119.9 & -180. & 4 & 3 & 2 & 0.235 \\
\hline
\end{tabular}

*: Angstroms, **: Degrees.

Furthermore, from the results of calculations optimized by fixing the structure of the dication of 3-typhoon tridentene to a plane, the estimated inversion energy $\Delta \mathrm{E}$ between the dication of 3-typhoon tridentene and dication of 3-cyclone tridentene (Fig. 7) was $9.19 \mathrm{kcal} / \mathrm{mol}$. As this value is about twice as large as the inversion energy of ammonia [8] and comparable to the energy of infrared radiation, it is suggested that the inversion between these two antipodes readily occurs at room temperature.

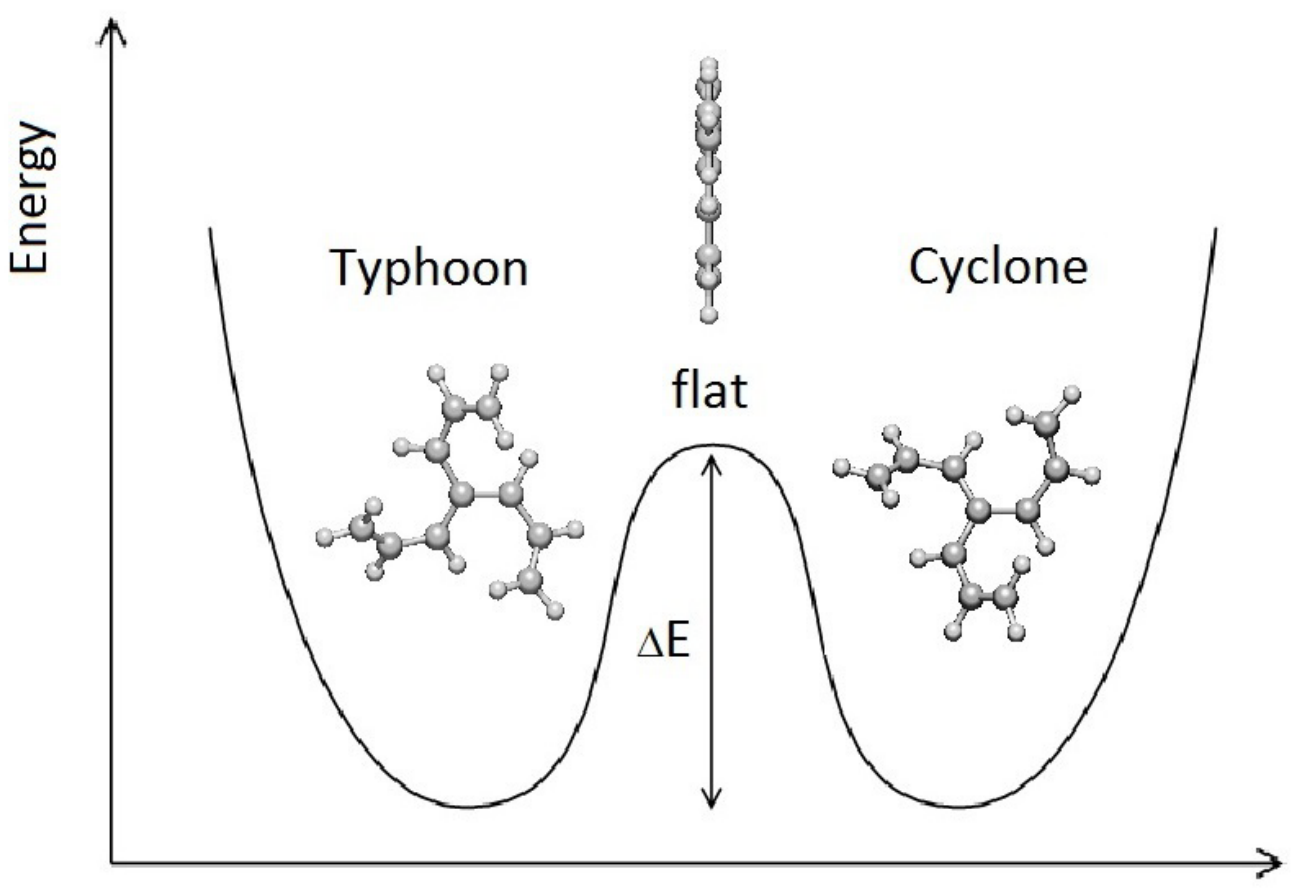

Reaction Coordinate

Fig. 7 Double-well potential of 3-tridentene inversion.

\section{§ III-4 Conclusions of this section}

The results of semiempirical molecular orbital calculations of 2-tridentene and 3-tridentene with spirally arranged linear conjugated system suggest the following conclusions. 
(1) The dication of 3-tridentene with spirally arranged linear conjugated system has a shallow bowl-shaped structure with left- and right-handed antipodes when the convex side is facing down.

(2) Based on the charge distribution of the optimized structure, the dication of 3-tridentene has a stereoselective binding potential, depending on the spatial symmetry of the charge distribution of the counterion.

(3) When 3-tridentene coexists with an electrically positive counterion, a dianion with planar structure may be produced via charge transfer.

(4) The inversion energy barrier between the dication of 3-typhoon tridentene and 3-cyclone tridentene is in the order of the thermal energy at room temperature.

In the future, we intend to design counterions with a steric charge distribution that enables the formation of ionic liquids with 3-typhoon tridentene and 3-cyclone tridentene.

\section{References for Section III}

[1] T. Ohmae, Journal of Computer Aided Chemistry, 19, 19-25(2018). in Japanese.

[2] T. Ohmae, Journal of Computer Aided Chemistry, 20, 18-22(2019). in Japanese.

[3] S. Huzinaga, "Molecular Orbital Theory”, Iwanami Shoten (1980), pp.330-334. in Japanese.

[4] O. Kikuchi, "Basic Quantum Chemistry”, Asakura Publishing Co., Ltd. (1997), pp.85-117.

[5] T. Itoh, T. Nogami, Oleoscience, 18, 165-174(2018). in Japanese.

[6] J. J. P. Stewart, J. Comput. Chem., 10, 221-264(1989).

[7] J. J. P. Stewart, “MOPAC2002 Manual”, Fujitsu Limited, Tokyo (2001).

[8] H. Kihara, N. Uchida, S. Ikuta, "Molecular Orbital Methods”, KODANSHA SCIENTIFIC LTD., (1994), p.168.

\section{Acknowledgements}

The author thanks Crimson Interactive Pvt. Ltd. (Ulatus) - www.ulatus.jp for their assistance in manuscript translation. 